\title{
METHODOLOGY TO ADMIT NEW FREIGHT TRAINS TO INTERNATIONAL TRAFFIC ACCORDING TO THE UIC
}

\author{
L. Cantone* \\ Department of Enterprise Engineering "Mario Lucertini" \\ University of Rome "Tor Vergata", Via del Politecnico 1, 00133, Rome, Italy \\ T. Durand \\ SNCF - Direction du Matériel, Le Mans, France \\ R. Karbstein \\ DB Systemtechnik GmbH, Minden, Germany \\ A. Ottati \\ Trenitalia S.P.A, Florence, Italy \\ * Corresponding Author email: Luciano.Cantone@uniroma2.it
}

\begin{abstract}
Current version of UIC Leaflet 421 provides a methodology based on statistical analysis to accept train compositions whose limits exceeds $2500 t$ and $700 m$ (locomotives excluded), for international traffic. This methodology does not consider explicitly trains with distributed traction/braking and their most relevant degraded modes. The paper shows a more general methodology to build statistically virtual trains, considering boundaries in terms of both train mass and length. The UIC approved TrainDy software can compute the longitudinal train dynamics (LTD) of these trains efficiently and accurately. The paper applies the new UIC Leaflet 421 to trains with distributed power and braking where the Traction Units (TU) communicate by means of GSM-R radio. Results show that in-train forces for $1500 m$ train, heterogeneously loaded, carrying up to 4800t, with four $T U$, are similar to those of already running trains, at least in nominal mode, i.e. when there is a proper communication between the TU.
\end{abstract}

Keywords: UIC Leaflet 421, Long train (LongT), Freight trains, GSM-R, Longitudinal Train Dynamics (LTD).

Cite this Article: L. Cantone, T. Durand, R. Karbstein and A. Ottati, Methodology to Admit New Freight Trains to International Traffic According to the UIC. International Journal of Mechanical Engineering and Technology. 11(6), 2020, pp. 41-51.

https://iaeme.com/Home/issue/IJMET?Volume $=11 \&$ Issue $=6$ 


\section{INTRODUCTION}

In Europe, the Railway Undertakings, which aim to reduce their green footprint and also to get more capacity from existing infrastructure (to increase the railway efficiency), are working to put in service longer and heavier freight trains. Typical maximum length of freight train is $740 \mathrm{~m}$, in Europe, and the train consist has one or two Traction Unit in front. There are also several cases of train consists with a remote Traction Unit placed at the end of the train and commanded by a driver. Mainly because of the lacking of the central coupler, the lengths of European freight trains are much lower than the counterparts of Australia, South Africa, and other Countries.

DB AG, from Germany, has launched several projects to increase the length of freight trains since 2008. Anyway, the first solution able to reach $1500 \mathrm{~m}$ was operated in France, by SNCF, during the FP7 Marathon Project, where two different trains where operated: one with electric traction units and a second with diesel traction units. Currently, within Shift2Rail Project, DB AG is working to an ambitious project on long trains, aiming to move a $1500 \mathrm{~m}$ train with up to four traction units.

Since freight trains usually employs the classic pneumatic brake, to put safely in-service trains formed by coupling two or more trains requires the study of the Longitudinal Train Dynamics (LTD) and the computation of in-train forces. [1]-[2] provide accurate reviews on LTD and modelling methods. Several software packages are able to address this topic, as mentioned in [3]-[6]; [7]-[8] provide a benchmark of some of them.

The numerical model introduced in [9]-[11] was subjected to an international process of validation and, in 2009, the UIC validated the software TrainDy [6], after several steps of intermediate validations [12]-[13], for the computation of longitudinal train dynamics (LTD). UIC also established a Special Group made by Faiveley Transport (a Wabtec Company), University of Rome "Tor Vergata", DB Systemtechnik GmbH, SNCF, Trenitalia and Knorr Bremse. TrainDy has been validated by means of a comparison against more than 30 experimental test trials, made available by DB Systemtechnik GmbH, SNCF and Trenitalia. Main characteristic of TrainDy is the capability to solve together the pneumatic problem (venting of brake pipe and filling of brake cylinders) and mechanical problem (computation of relative approach between adjacent wagons). This feature makes TrainDy particularly feasible to study new compositions of trainsets or to optimize train operations [14]-[15].

For this reason, the UIC recently launched two projects during which the TrainDy software has been used and improved: the "Rules for the consist and braking of international freight trains" (IRS 421) and the project "Long trains with distributed power" (LongT) [16]. The first project aims to: a) study the effect on LTD of some wagons components, such as the type of control valves, buffers/draw gears, and so on; b) automatically compute statistic trainsets by means of TrainDy; c) modify the IRS 421, as a consequence. The second project aims to find the best combinations in terms of train length/hauled mass for trains with distributed power system, communicating by GSM-R radio technology, see also [17] about the former FP7 Marathon Project. The UIC 421 and LongT projects, together, facilitate the European implementation of new heavy hauled freight trains with length up to $1500 \mathrm{~m}$, moved by up to four Traction Units (TU); this can positively affect the railway business by increasing the freight transportation efficiency.

This paper reviews the methodology proposed by the UIC Leaflet 421 to admit new freight trains to the international traffic and applies it to trains with multiple traction units placed along the train and communicating by GSM-R (as possible radio communication technology), aiming to show that it is possible to safely operate such trains in Europe. 


\section{GENERATION OF RANDOM TRAINS}

The task of generating random trains is crucial for a statistical investigation on in-train forces of a freight train [18]; this topic is, in turn, crucial for a risk assessment of new freight trains, as far as LTD is concerned. Generation of random trains, within the IRS 421 Project, is possible by means of two algorithms as described in [19]. Here it is described, just one of these two algorithms.

Figure 1 represents by pictures the process to generate random virtual trains according to the UIC Leaflet 421; Figure 2 displays the same process, more formally, where it clearly shows the possibility to generate trains with desired bounds in terms of hauled mass and train length.

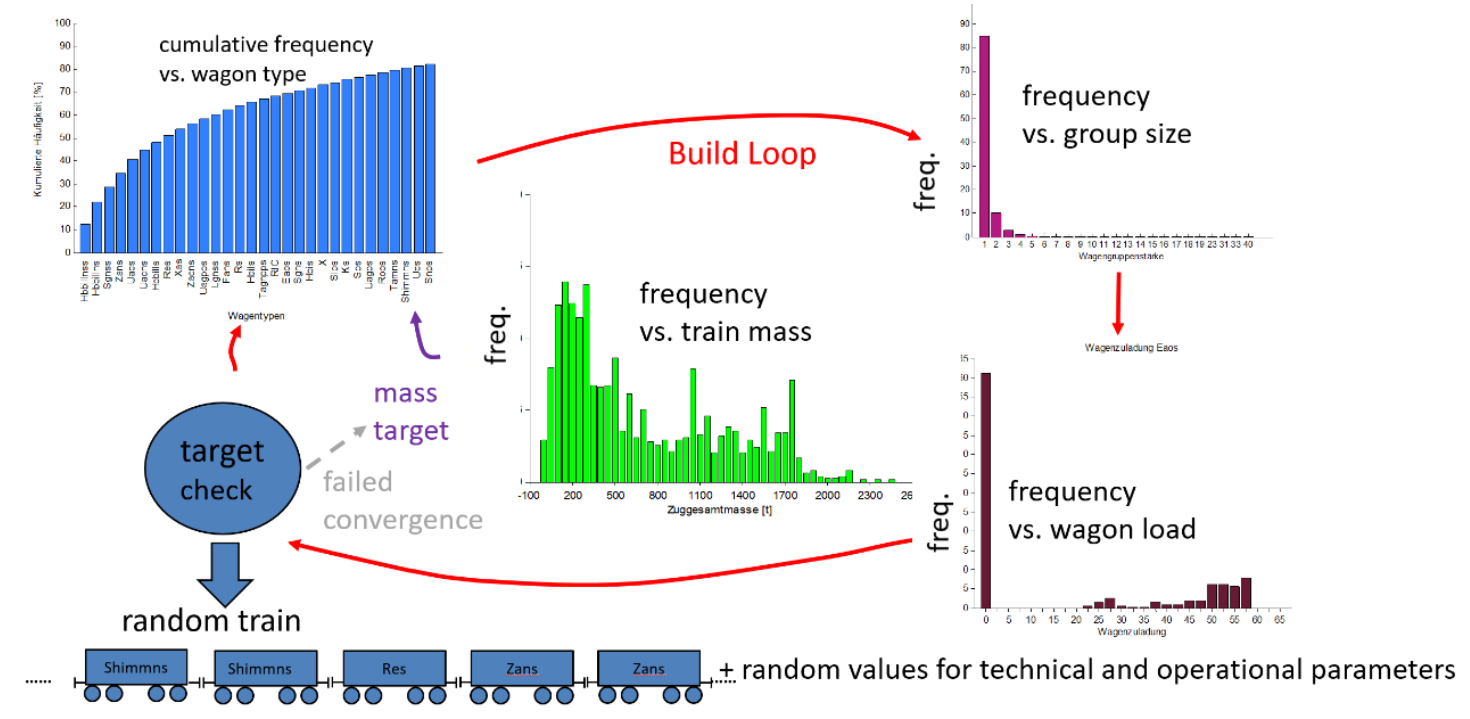

Figure 1 Pictorial representation of the random process to generate virtual trains

The starting point is the mass distribution of existing trains in a Country or a smaller area, possibly weighted with the distance covered by the train. From each train, it is possible to derive the wagon in the composition and therefore a relationship between the cumulative frequency and the wagon type. Moreover, knowing the number of consecutive wagons with the same type and payload, it is possible to build a histogram of the group of wagons size. Lastly, it is possible to associate to each wagon a distribution of carried payload. By knowing these quantities, quite readily available to each Railway Undertaking, it is possible to build random virtual trains, according to Figure 2.

Since the number wagons equipped with composite brake blocks type LL and $\mathrm{K}$ is increasing in the last years, the original version of TrainDy software has been enriched with the modules to handle these types of wagons, described in [20]-[21].

The two algorithms have been checked against a similar algorithm made available by DB Systemtechnik, which does not automatically manage the train length limits, and the results from the new tool are equivalent to those provided by the DB systemtechnik tool. This tool provides to UIC Railway Undertakings a common simulation platform to generate interoperable freight trains and to compute them with TrainDy software. 


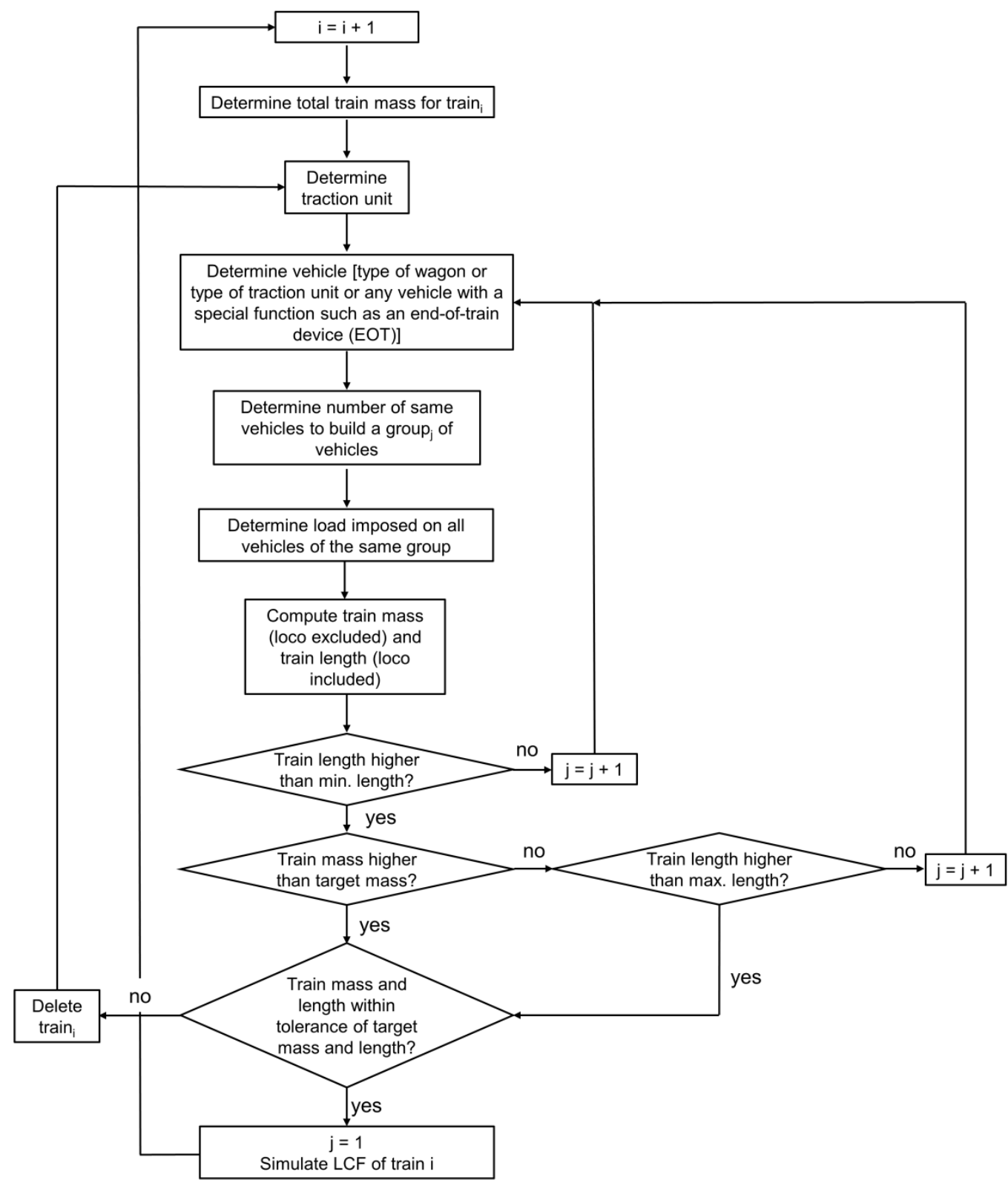

Figure 2 UIC 421 flowchart for bounded train length

\section{RELATIVE APPROACH}

There are two ways to admit a new train type to international traffic, according to the UIC Leaflet 421: the absolute and relative approach. This paper deals only with the relative approach, which is more straightforward and requires a faster approval process from the National Safety Authorities, typically. This approach fulfils the Common Safety Methods (CSM) adopted by the European rules (Commission Implementing Regulation (EU) 2015/1136 of 13 July 2015). According to this approach, a new train type (or new system) is admitted to traffic, therefore considered safe, if it is safer than those existing and already running (reference system). In this context, the safety is evaluated by considering in-train forces of new and existing random trains generated according to flowchart in Figure 2. Intrain forces are relevant for the safety of a train, since high in-train compressive forces or longitudinal compressive forces (LCF) can cause a train derailment, whereas high in-train 
tensile forces or longitudinal tensile forces (LTF) can cause a train disruption i.e. braking of the train in two (or more) parts. What is important is the probability that LCF can exceed the permissible LCF and that LTF can exceed the permissible LTF. The UIC Leaflet 421 does not provide methods to compute the permissible LTF, actually; instead it provides a method to compute the permissible LCF, described in the next section.

\subsection{Permissible LCF}

The experimental tests according the UIC Leaflet 530-2, see also [22], are the starting point for the determination of the permissible LCF, even if it is possible to compute permissible values by means of trusted computer packages or by means of extrapolations as in [21].

Once the permissible LCF of empty wagon in an S-shaped curve of $150 \mathrm{~m}$ radius has been determined, the permissible extrapolated LCF of the wagon is computed by the following rules:

- According to the track radius of curvature: $1 \mathrm{kN} / \mathrm{m}$ for two-axle wagons and $2 \mathrm{kN} / \mathrm{m}$ for two-bogie wagons.

- According to the additional payload: $8 \mathrm{kN} / \mathrm{ton}$

- According to the buffer plate radius: when it increases from $1500 \mathrm{~mm}$ to $2750 \mathrm{~mm}$, the permissible LCF increases by:

○ $40 \mathrm{kN}$ in $150 \mathrm{~m}$ curves

- $30 \mathrm{kN}$ in $190 \mathrm{~m}$ curves

○ $15 \mathrm{kN}$ in $300 \mathrm{~m}$ curves

However, the extrapolated permissible LCF does not exceed $400 \mathrm{kN}$, actually.

As general guidance, on a track with a radius of $150 \mathrm{~m}$ an empty two axle wagon has a permissible LCF of $200 \mathrm{kN}$, whereas it is $240 \mathrm{kN}$ for a bogie wagon.

Unless a more refined study, which couples the in-train compressive forces with the position of the train on the track, is performed, it is possible to consider the minimum radius of curvature of the track in a critical/interesting area. In this way, in favor of safety, the highest in-train compressive force is assumed to always occur on that critical position, which is not the case, of course.

\subsection{Case of Distributed Power/Braking}

The train operations, which have to be simulated in the comparison between the reference system and the new system, are those that typically occur during the normal operation, of course, since safety is concerned, the relevant train operations are for example: full traction followed by an emergency braking, emergency braking and full-service braking from coasting conditions. When the new system has a distributed power/braking, as those considered in this paper, it is important to simulate not only the nominal train operations, but also the degraded mode of train operation, i.e. when the radio communication between the traction units fails. Consider that also initial speed variations must be taken into account, especially if the distribution of initial speeds is different between the two systems to be compared.

An easy method to compute the occurrence of degraded mode that would provide the same level of safety of the new system and the classic system is here introduced.

The first step is to generate a number of statistic trains according to the methodology described above in section 2: usually, 1000 trains are a suitable number according to the experience. These trains must be simulated in the same way they are or will be operated. Then, for each train operation and different initial speed, which occur with fraction $p_{i}$, it is necessary to determine the probability of derailment $P_{i}$, i.e. the probability that the ratio 
between the longitudinal compressive force and the permissible compressive force is bigger than 1 .

Therefore, the probability of derailment of reference system is $P^{r e f}$ is computed: as.

$$
P^{r e f}=\sum_{i=1}^{n} p_{i} P_{i}, \quad \sum_{i=1}^{n} p_{i}=1
$$

Where:

- $p_{i}$ is the occurrence of each train operation/different initial speed, e.g. full service brake, emergency braking, ...

- $\quad P_{i}$ is the probability of derailment with train operation $i$

- $n$ is the number of different train operations/ initial speeds considered in the analysis.

If the new system does not have any degraded mode, it is necessary to compute the probability of derailment for the new system $P^{n e w}$, in the same way as above. If the new probability is below or equal to $P^{r e f}$, then the new system can be admitted to the international traffic.

If the new system has a distributed traction/braking, it is necessary to consider also the degraded modes, i.e. when there is a communication loss between the traction units and the train is performing a service braking, a traction, and so on. In this case, it is necessary to compute the probability of derailment in degraded mode $P_{i}^{D}$, too.

Therefore, the probability of derailment of the new system (with degraded mode) - $P^{\text {new }}$ :

$$
P^{\text {new }}=\sum_{i=1}^{n} p_{i}\left[(1-\alpha) P_{i}^{N}+\alpha P_{i}^{D}\right]
$$

Where:

- $\quad \alpha$ is the occurrence of degraded mode.

- $P_{i}^{N}$ is the probability of derailment for train operation $i$ in nominal mode

- $P_{i}^{D}$ is the probability of derailment for train operation $i$ in degraded mode.

By equating $P^{\text {new }}$ and $P^{r e f}$ it is possible to compute the occurrence $\alpha$ of degraded mode that makes the new system safe as the reference system. If this value is above (i.e. higher than) the estimated or measured occurrence of degraded mode, the new system is safer than the reference system. Currently, $\alpha$ is difficult to estimate but it is closely linked to the reliability of radio technology employed.

\section{RESULTS}

Results reported in this paper refer to DB AG trains and are statistically computed from a database of more than $2 \cdot 10^{5}$ trains, considered according to their running distance.

First results refer to classical trains (i.e. Reference System) extracted from above database having mass, length and corresponding brake position according to current UIC Leaflet 421 limits; in addition, heavy hauled, almost homogeneous, freight trains with hauled mass up to 5500 t are considered with label GH in Figure 3. This figure shows the cumulative probability of in-train forces for an emergency braking (EB) starting from $30 \mathrm{~km} / \mathrm{h}$ in (a) and in (b) an acceleration from steady conditions up to $30 \mathrm{~km} / \mathrm{h}$ followed by an emergency braking (label N202). In Figure 3 and following figures each dot refers to a different train and negative values refer to Longitudinal Compressive Forces at $10 \mathrm{~m}$ whereas positive values to Longitudinal Tensile Forces at $2 \mathrm{~m}$ : the former are relevant for derailment risk, the latter for disruption risk and for draw gear maintenance. 
Higher in-train forces are reached during the train operation N202, in agreement with Railway Undertakings experience. Figure 4 refers to trains with distributed power system (DPS) formed by coupling two trains: the first with average length of $400 \mathrm{~m}$ and originally in LL, the second with average length of $300 \mathrm{~m}$ : when the two trains are coupled, the resulting train runs in $\mathrm{G}$ brake position. In this figure, D202 refers to degraded mode of train operation N202 and the same for D204 that represents the degraded mode of emergency braking, whereas "FS" stands for Full-Service braking. In this figure, wagons in (a) are equipped with traditional cast iron brake blocks, whereas wagons in (b) are equipped with CBB type LL. When the train is connected, the nominal delay in communication between the traction units is $2 \mathrm{~s}$.

Last results, in Figure 5, refer to trains formed by connecting four trains originally in GP (when the train is coupled it runs in $\mathrm{G}$ ) and resulting in a train of $1500 \mathrm{~m}$ and heterogeneous hauled mass up to 4800t. The in-train forces of this train, in nominal (see "EB" and "N202") and degraded mode ("D204" and "D202") are compared against the in-train forces of reference system in (a) and in (b) (brake regime $\mathrm{P}$ is not considered to simplify the figure). Comparing results of

Figure 5 (c) against (a) and (b), it is straightforward to note that in nominal mode (i.e. when the DPS works fine) the in-train forces are similar, in terms of their maximum values, to those of the reference system, especially for heavy hauled trains running in G mode, see label "GH".
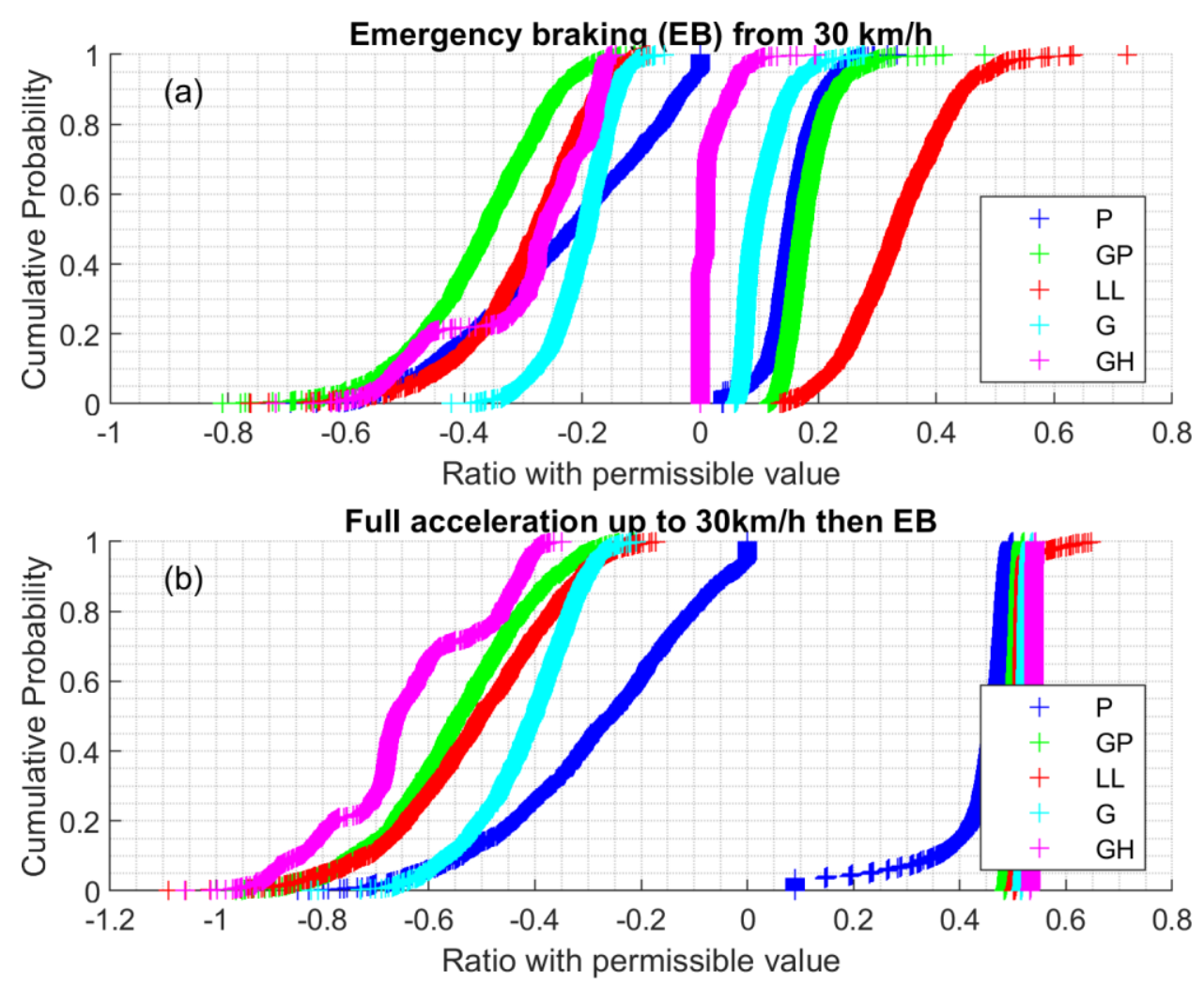

Figure 3 Ratio of longitudinal forces with their permissible values: (a) emergency braking from 30 $\mathrm{km} / \mathrm{h}$ and (b) full traction up to $30 \mathrm{~km} / \mathrm{h}$ followed by an emergency braking 

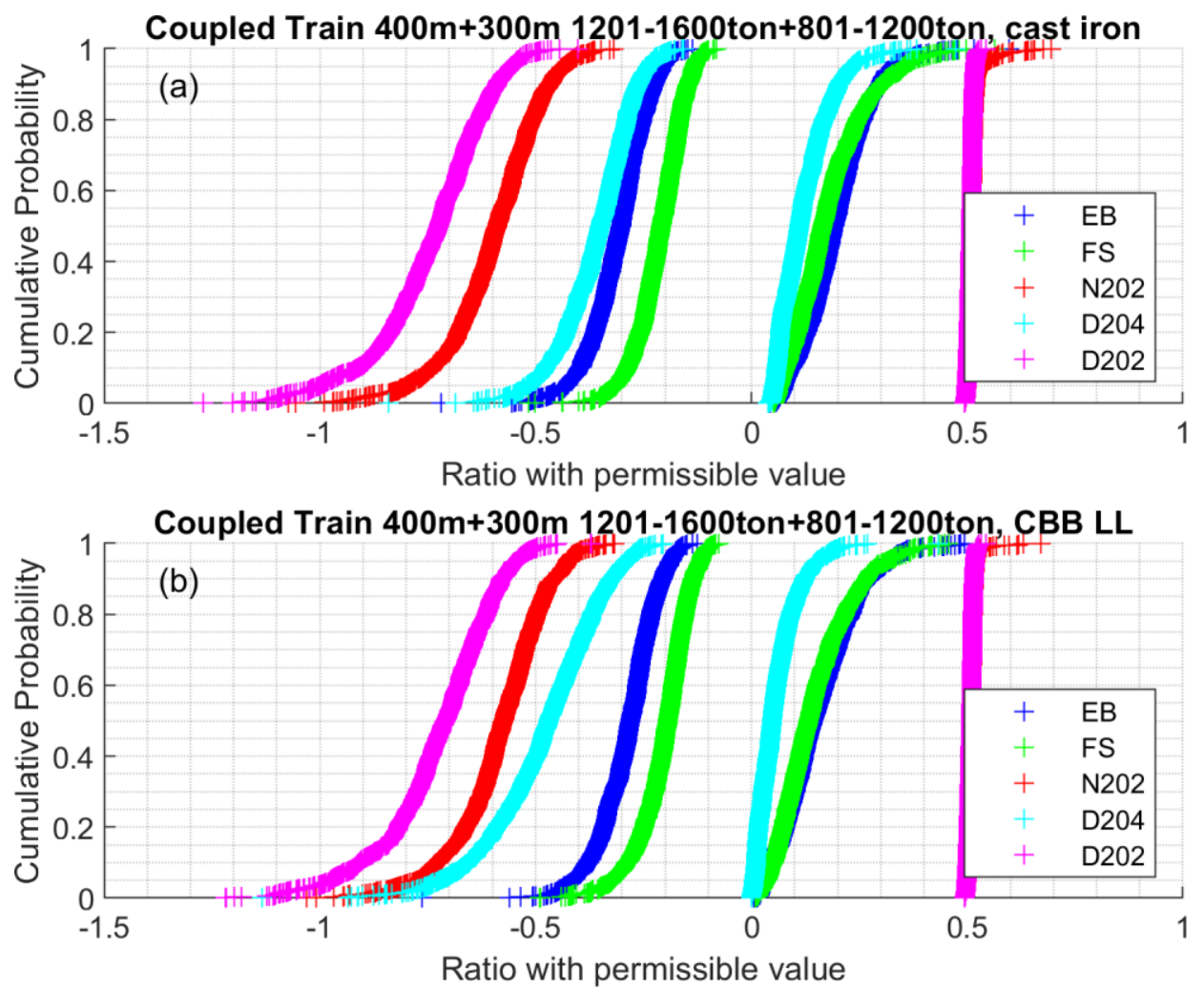

Figure 4 Ratio of longitudinal forces with their permissible values for coupled train: (a) all cast iron and (b) composite brake blocks (CBB) type LL
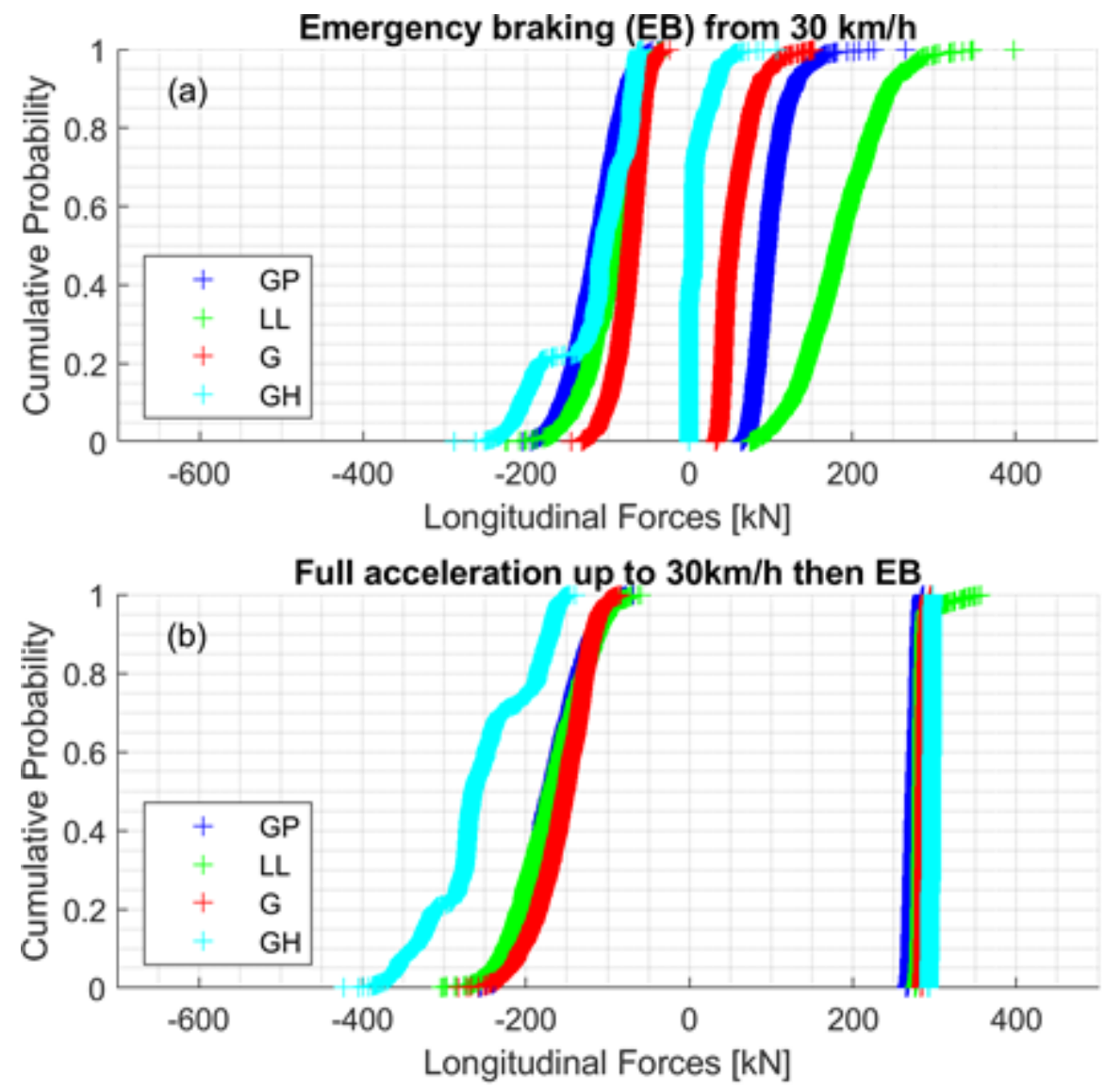


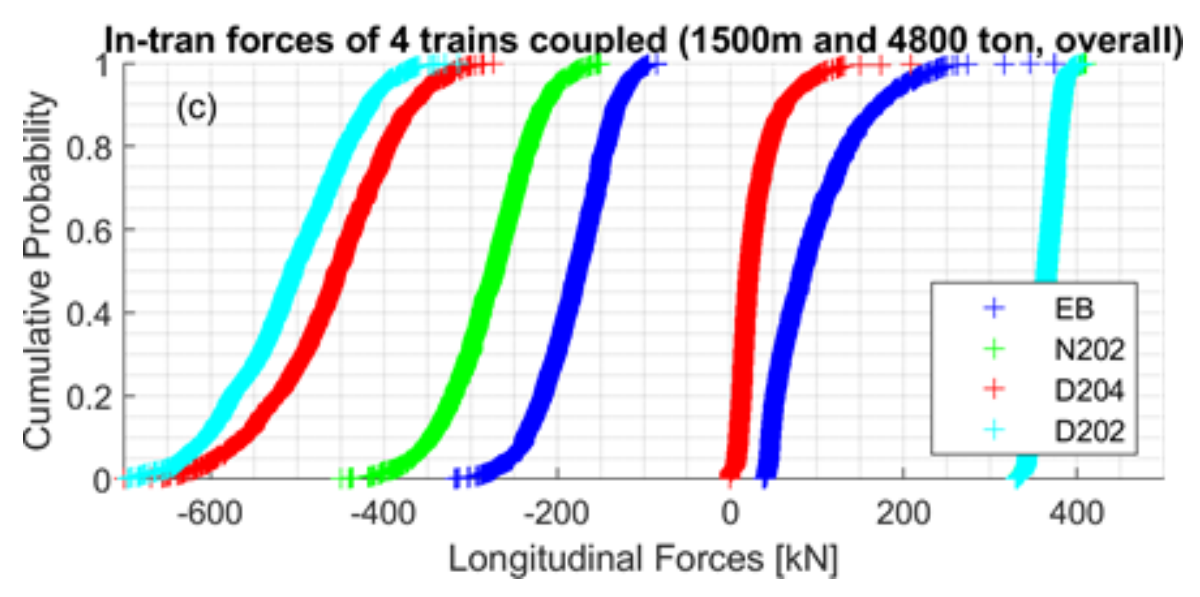

Figure 5 In-train forces of reference system trains (a) and (b) compared with those of connected train with four TU and $1500 \mathrm{~m}$ length (c)

On the contrary, when the DPS has a general failure, the in-train compressive forces become dangerous, especially if they are experienced on an S-shaped curve with short radius of curvature [22].

\section{RESULTS DISCUSSION AND CONCLUSIONS}

Availability of a common trusted software for Longitudinal Train Dynamics (LTD), as TrainDy, facilitates the agreements on interoperable freight trains; by means of new IRS 421 Project, Railway Undertakings can also benefit of a common random trains' generator, which allows a safety assessment of new trainsets. The paper shows some results of new trainsets with Distributed Power System (DPS) commanded by GSM-R technology. These trains should be compared, with respect to LTD, to already running trains (i.e. Reference System) both in nominal mode (i.e. DPS works fine) and in degraded mode (i.e. DPS has a failure), for most relevant train operations. Implementation of GSM-R within commercial Traction Units (TU) offers an average delay in communication of $2 \mathrm{~s}$; this delay is kept if the TU are more than 2, i.e. from leading TU to guided TU there is always around $2 \mathrm{~s}$ of delay, resulting in an almost synchronous braking of guided TU. This feature is an advantage for long heavy hauled freight trains with up to four TU as the results of Fig. 5 show, where, even in degraded mode, the in-train compressive forces can be safely accepted if they are experienced on a curve with radius of curvature higher than $300 \mathrm{~m}$. This consideration implies that LTD analysis must be coupled with an analysis of the railway routes where these trains are implemented and about the likelihood that a high value of in-train compressive force can be experienced on a track section with small radius of curvature.

\section{REFERENCES}

[1] Wu Q., Spiryagin M and Cole C. Longitudinal train dynamics: an overview. Vehicle System Dynamics, 54(12), 2016, pp. 1688-1714.

[2] Cole C., Spiryagin M., Wu Q. et al. Modelling, simulation and applications of longitudinal train dynamics. Vehicle System Dynamics, 55(10), 2017, pp. 1498-1571.

[3] Kovalev R., Sakalo A., Yazykov V. et al. Simulation of longitudinal dynamics of a freight train operating through a car dumper. Vehicle System Dynamics, 54(6) 2016, pp. 707-722.

[4] Belforte P., Cheli F., Diana G. et al. Numerical and experimental approach for the evaluation of severe longitudinal dynamics of heavy freight trains. Vehicle System Dynamics, 46(S1), 2008, pp. 937-955. 
[5] Shabana A. A., Ding L. and Aboubakr A. Use of non-inertial coordinates in the analysis of train longitudinal forces. Journal of Computational and Nonlinear Dynamics, 7(1), 2012, https://doi.org/10.1115/1.4004122.

[6] Cantone L. TrainDy: The new Union Internationale des Chemins de Fer software for freight train interoperability. Proceedings of the Institution of Mechanical Engineers, Part F: Journal of Rail and Rapid Transit, 225(1), 2011, pp. 57-70.

[7] Spiryagin M., Wu Q. and Cole C. International benchmarking of longitudinal train dynamics simulators: benchmarking questions. Vehicle System Dynamics, 55(4), 2017, pp. 450-463.

[8] Wu Q., Spiryagin M., Cole C. et al. International benchmarking of longitudinal train dynamics simulators: results. Vehicle System Dynamics, 56(3), 2018, pp. 343-365.

[9] Cantone L., Crescentini E., Verzicco R., Salvini P. and Vullo V. Development and validation of a fluid-dynamic model for the simulation of the main brake pipe of a railway vehicle [Sviluppo e validazione di un modello fluidodinamico per la simulazione della condotta generale di un convoglio ferroviario], Ingegneria Ferroviaria, 62(1), 2007, pp. 27-38.

[10] Cantone L., Crescentini E., Verzicco R., Salvini P. and Vullo V. A numeric model for the study of brake releasing operation [Modello numerico per lo studio della manovra di sfrenatura], Ingegneria Ferroviaria, 62(7-8), 2007, pp. 575-588.

[11] Cantone L., Crescentini E., Verzicco R. and Vullo V. A numerical model for the analysis of unsteady train braking and releasing manoeuvres, Proceedings of the Institution of Mechanical Engineers, Part F: Journal of Rail and Rapid Transit, 223(3), 2009, pp. 305317.

[12] Cantone L. and Palazzolo A. Pneumatic validation of traindy with Trenitalia experimental data [Validazione pneumatica di TrainDy con dati sperimentali Trenitalia]. Ingegneria Ferroviaria, 63(5), 2008, pp. 409-418.

[13] Cantone L., Negretti D., Palazzolo A. and Karbstein R. Dynamic validation of the new International Union of Railways (UIC) simulator for the longitudinal dynamics of trains, namely, TrainDy with experimental data from Deutsche Bahn (DB) and Trenitalia [Validazione dinamica di TrainDy con dati sperimentali DB e Trenitalia], Ingegneria Ferroviaria, 64(2), 2009, pp. 165-172.

[14] Cantone L., Durand T. and Ottati A. Effect of braking regime on train disruption risk, Proceedings WCRR 2016, $11^{\text {th }}$ World Congress on Railway Research, Milano, Italy $29^{\text {th }}$ May- $2^{\text {nd }}$ June 2016.

[15] Cantone L. and Arcidiacono G. A study on releasing manoeuvre to improve freight safety and efficiency, International Journal of Mechanical Engineering and Technology, 9(3), 2018, pp. 899-909.

[16] Cantone L., Durand T., Karbstein R. and Ottati A. Application of new UIC Leaflet 421 methodology to new freight train compositions with up to four traction units in distributed traction/braking, Proceedings WCRR 2019, 12 ${ }^{\text {th }}$ World Congress on Railway Research, Tokyo, Japan, $28^{\text {th }}$ October- $1^{\text {st }}$ November 2019.

[17] Durand T. and Cantone L., Risks of derailment on very long remote control trains, Proceedings WCRR 2016, $11^{\text {th }}$ World Congress on Railway Research, Milano, Italy $29^{\text {th }}$ May- $2^{\text {nd }}$ June 2016.

[18] Cantone L. and Ottati A. Methodologies for the hauled mass increase of freight trains in accordance with Fiche UIC 421 [Metodologie per l'incremento della massa rimorchiata dei treni merci in conformità alla Fiche UIC 421]. Ingegneria Ferroviaria, 70(2), 2015, pp. 109-128. 
[19] Cantone L. New Random Trains Generation According to UIC Code 421. International Journal of Mechanical Engineering and Technology, 9(10), 2018, pp. 890-899.

[20] Cantone L. and Ottati, A. Modelling of friction coefficient for shoes type LL by means of polynomial fitting. The Open Transportation Journal, 12(1), 2018, pp. 114-127.

[21] Arcidiacono G. and Cantone L. A model of control valve for wagons equipped by kblocks. International Journal on Advanced Science, Engineering and Information Technology, 8(1), 2018, pp. 285-290.

[22] Krishna V. V., Berg M. and Stichel S. Tolerable longitudinal forces for freight trains in tight S-curves using three-dimensional multi-body simulation. Proceedings of the Institution of Mechanical Engineers, Part F: Journal of Rail and Rapid Transit, 234(5), 2020, pp. 454-467. 